\title{
Ostensibly indirect narration in films and motion pictures
}

\author{
MAREK HENDRYKOWSKI \\ Institute of Film, Media and Audiovisual Arts \\ Adam Mickiewicz University, Poznań, Poland
}

\begin{abstract}
AвSTRACT. Hendrykowski Marek, Ostensibly indirect narration in films and motion pictures. „Images” vol. XXVI, no 35. Poznań 2019. Adam Mickiewicz University Press. Pp. 209-218. ISSN 1731-450X. DOI 10.14746/i.2019.35.11.

The article proposes the hypothesis that on the basis of analytical and interpretative practices, when describing, analysing and interpretating moving images, a dichotomous, binary division into objective and subjective images is a highly questionable move: it does not lend itself to an absolutely unequivocal resolution. In film, as in the field of moving images as a whole, there is no objective narration, just as there is no subjective narration. What emerges is an ostensibly dependent narration (or ostensibly independent), blending and merging both of these aspirations in diverse ways.
\end{abstract}

KEYwORDS: narration, moving pictures, image, reality, fiction film, documentary, subjectivity, objectivity, communication, film, audiovisual culture

\section{Objectivisation and subjectivisation of the message}

For over a hundred years now the issue of the objectivism/ objectivity of cinematic representation has been the focus of ongoing debate, albeit with lesser or greater intensity. The crux of the dispute is the question of the reliability of such a representation and therefore has to be considered of utmost importance. Various concepts have been put forward and a variety of arguments, both against and in favour, have been identified. Scholars differ in their perspective on this problem, i.e. Münsterberg proposes a different view to Ingarden, Bálazs to Arnheim, Jakobson to Eichenbaum, and yet another solution is suggested by Kracauer or Bazin.

Generally speaking, in each case, the subject of the debate is the ontological status of moving images with reference to the reality they are supposed to represent. Who presents it? Is it the human or the medium that is communicating? The way the camera works, the sound and visual imprint of the reality filmed offers objectivity of the image. And it would be almost ideal, if not for the bothersome hint of subjectivity that disturbs the image's workings and renders it questionable and not entirely trustworthy. As a consequence, the perfectly "objective" medium loses the objectivity of its message, due to the subjective operations of its users. But is it truly so? Perhaps it is worth trying a different approach, one that is in line with the actual practice of communicating?

The hypothesis put forward here is of a premise inferred from the analytical and intepretational approach, according to which, when interpreting moving images, the dichotomy of the binary distinction between the objective and the subjective imaging simply fails. There are no means that would allow for identifying such a clear-cut differentiation. It is not possible to identify it in fictional film, even though this type of film could be expected to have subjective elements as supposedly obvious features of any fantasy. Neither is it possible to trace the distinction in fact-based films, although in this case we would expect an almost entirely objective image, i.e. completely freed of any trace of the subjective. 
For the researcher there seems to be no way out of this highly inconvenient situation. Nevertheless, we will try and point towards a solution here, based on the premise that distinguishing film images using objectivity or subjectivity as the key feature produces more complications than benefits for researching narration, since it is determined by a fallacious presumption about the existence of such a dichotomy, which, as it turns out, is actually far from obvious. The problem of maintaining this distinction manifests itself in any type of message or piece of work composed of moving images. It surfaces not only with reference to the characteristics of a single shot or scene, but also when trying to examine the semantic structure of the message as a whole.

Probably the most complicated case in this perspective is documentary, with its inherent feature of the intention to show or to film "things as they are". What is striking here is the unjustified supposition that images are registered automatically, free of human interference, which in turn is supposed to guarantee their inherent objectivity. In light of this erroneous presumption, documentary is seen as an ideal audiovisual copy of external reality, a "de-textualised" product, free from any semantization of the world it is supposed to be representing.

Once the message-creating role of the subject is removed, it leads to the conclusion that the 'pre-filmed' reality, which is registered through the camera and microphone, offers its objective image 'by itself'. This ideal of 'semantic' transparency already permeated the awareness about film as a medium at the onset of the existence of cinematography (cf. the $19^{\text {th }}$-century concept of film as a historical source defined by Bolesław Matuszewski in 1898). It would also set the tone for the future experiments of documentary film-makers, as well as the trajectories of theoretical analysis on the particularities of documentary.

Documentary film-making (e.g. Muybridge, Edison, Lumière Brothers, Méliès, Flaherty, Wiertow, Cavalcanti, Pudowkin, Grierson, Ivens, Buñuel in his "Land Without Bread") is far ahead of the theoretical analysis of the time. Up until Kracauer's study, film theory missed out on the key issue of the narration structure and the narrative nature of documentary. It has to be highlighted here once again that the film-making practice remained a step ahead of theory, despite the fact that the decades-long illusion of 'non-textuality' and 'subjectlessness' of documentary was already questioned and shattered by the inevitability of artistic means of expression that essentially determine the message in each case.

The question that immediately comes to mind is "whose means of expression"? Starting from the very decision to record and then the choice of the way this is going to be done (i.e. the vantage point, the length of the shot, the lighting, black and white or colour, the drama of the event filmed, cropping) and, finally, the selection of the recorded material, all these are not merely accidental. Although the two main factors that determine editing seem to be sidelined in documentary to the point of being invisible, they are still in fact governed by a specific set of rules. These rules, even if not identical, at least correspond to those which govern any other piece of communication in the form of moving images (not neccessarily recorded on film).

Therefore, the objectivity of documentary immediately turns out to be a debatable category that is also provisional in its application, i.e. it is encumbered with a high degree of doubt as regards its form and cognitive merits. To explain the issue raised here it is not even necessary to reach for the obvious example of mockumentary, as it is also clearly visible when analysing the classic documentary strategies. The objectivity of the camera as the reporter and chronicler, or the camera as a witness, or a judge or accuser, all those prove to be merely the result on the screen of a series of purposeful decisions of a text-generating nature.

The communicative effect that is discussed here is the result of various attempts to objectivise what is in fact a subjective perspective, i.e. characterised by its agent, "broadcaster" and 
author, and ultimately, always being somebody's view. This is unsurprising, as we are ultimately dealing with a series of communications, declarations or statements formulated in one way or another in the form of a documentary. In other words, these are moving image communications, whose creator, through an arbitrary, subjective choice and selection of particular elements of the film material, attempts to achieve the referential value (objectivity) of the representations contained within the material.

It is no coincidence that the classic documentary masterpieces achieved the top level of the objectivisation of documentary expression paradoxically through the subjective interference of the film-makers as regards the selection and order of the material presented, e.g. Robert Flaherty's Nanook of the North (1922), Dziga Vertov's Man with a movie camera (1929), Leni Riefenstahl's Triumph of the Will (1935), Night Mail by Harry Watt and Basil Wright (1936), Charles Ridley's Germany Calling (1941), and Know Your Enemy: Japan by Joris Ivens (1945).

Having discerned this particular paradox, Alicja Helman draws conclusions as to its consequences for the theory of the documentary poetics as a genre, as she writes: "Flaherty's biographers frequently quoted the claims that Nanook is made as if from the point of view of the Inuits themselves, "from within", rather than from the vantage point of an objective, disengaged observer [...]. While filming, Flaherty records the process of an emergent form, as if the camera was "destilling" the poetic image of the penetrated reality by interpreting, describing and naming the phenomena. As a film-maker, he adopts the same attitude as the traveller and researcher, i.e. the process of film-making was an end in its own right, similarly to the journey into the interior of the unknown land [...]. He turns the penetration of the Polar circle into a fruitful artistic activity of unearthing sense from under the everyday human struggle against the severity of nature, which requires constant alertness, readiness and agility, as any false move can spell death. Meaning reveals it- self in material references, i.e. in form. Their natural expression carries an impression of truth, simplicity and beauty." [F1]

The description cited here constitutes the significant unification of what tends towards objectivisation, on the one hand, and what derives its meaning from the subjectivisation on the other. Essentially, cinematographic narration intertwines objectivizing and subjectivizing factors in its examination of reality. It contains a definite vision of the world with the human presence and the human situation: not only the protagonist (present or absent on the screen), or the perceiver, ever-present and participating in the message.

\section{Ostensibly direct narration}

This part of the present discussion engages in a polemic with the long-established schematic approach to film narration which tends to categorise all its possible manigestations into the two rigid types, i.e. objective and subjective narration. However, what works in theory does not necessarily work in practice. The main problem lies in the fact that this simplified reflection so common in research, stands in striking opposition to communication practice.

A more in-depth analysis of the semantic structure of any given audivisual message in the form of moving images reveals the blurred fluidity and the far-reaching inaptitude of this distinction. This is because neither the whole film, nor its components, such as particular frames, scenes, editing segments or sequences, can be assigned and classified as either purely "subjective" or "objective". Any such binary distinctions turn out to be unconvincing and dubious.

Similarly, it is impossible to conclude whether a film/message/communication as a whole remains in its entirety explicitly "objective" or "subjective". Both these categories, deprived of any precise definition with reference to narration in moving images, are of an unclear and provisional nature, also burdened with axiology. In a nutshell, these terms simply do not stand the test of descriptive, analytical 
and interpretative procedure, as they percipitate misunderstanding and, to a certain degree, obvious controversy.

It is inordinately difficult to resolve if our contemporary reality as seen through, for instance, Godfrey Reggio's lens (vide Koyaanisqatsi) unfolds in the viewer's eyes as a narratively objective representation, or just the opposite, i.e. an exceedingly subjective one. I assume that both these answers and descriptive options are on an equal footing here. However, it becomes very interesting from the researcher's perspective if we put forward a propositon that the subjective and the objective in moving image communication do not simply occur consecutively, but also simultaneously at the same point in the particular piece of the message. At first sight, this idea seems out of the question, logically implausible and unattainable from the practical image-making point of view. Nevertheless...

Let us find an example exactly where we would least expect it, i.e. in a classic Hollywood production. The exemplary case will come from the well-known western My Darling Clementine (1946). John Ford, the unparalled master of narration, was a 'direct descendent' of David Wark Griffith. His films, including My Darling Clementine, are usually treated as paragons of objective narration in an epic work, whatever this term is supposed to stand for in this case. Let us now put it to the test focusing on the method of image creation applied by the author. For this analysis, I have selected an inconspicuous short sequence of Sunday in Tombstone featuring Sheriff Wyatt Earp and Miss Clementine Carter, who is leaving the town after an extremely unpleasant meeting with her former lover.

Hotel lobby. Following the conclusive breakup with Doc Holiday, Clementine waits with her baggage for the stagecoach to arrive to take her on a long journey. Decked out in his 'civies' and generously sprinkled with thyme by the barber, Sheriff Earp saunters around the lobby. From his visible microbehaviours the viewer can discern that he is no entirely indifferent to the beautiful woman. Likewise, she does not shy away from his company. The sheriff knows that Doc has shunned her affections. After briefly exchanging pleasantries, Wyatt Earp and Clementine Carter decide to go to a dance together. The elegantly dressed woman takes the man by the arm. Both walk down the Main Street of Tombstone, shielding themselves from the sun in the shade of the buildings. On arriving and listening to a speech initiating construction of the town church, they are called in by the compere to take the distinction of having the first dance. We observe their lively dance. Wyatt's two brothers arrive by horse and trap. That is all.

At face value, in Ford's narration style there is not even the slightest trace of anything that might deprive it of the transparency of the camera's objectivism accompanying the events as they unfold. Is it really so? The viewer is almost unwittingly led into the narrator's subjectivizing view, which questions and breaks the transparency effect of the depiction. In the scene of the sheriff's stroll with Clementine, Ford stages the moment in which the couple pass the town barber standing outside his shop. Hence, we have a shot of the couple he observes. This is the point at which the narrator almost imperceptibly takes leave of his hitherto objective chronicling of events and introduces an extra pair of eyes to the screen.

The barber observes the sheriff's stroll with Miss Carter, seeing them off with a knowing look and disapproving smirk. We share this split perspective with him: without a subject on the one hand, and subjective on the other. Into the objectivizing narrative framework (viewing the scene from 'outside') the comic figure of the barber is discreetly introduced, and with him a subjectivizing perspective (narration from inside'). The narrator of My Darling Clementine uses exactly the same strategy a few minutes later, i. e. first showing a couple dancing from the vantage point of the compere and other people participating in the event, and later at the end of this sequence making the two Wyatt brothers turn up in a coach who make their own short comment with a slight hint of irony watching the sheriff dance. The addressee of the narration 
is faced here with the same kind of duality that has been discussed before, i.e. a situation on the screen where the objective intertwines and interferes with the subjective representation.

Objective and yet subjective? Or maybe one and the other, in an intricate combination of their features and screen contradanse? As is revealed by this analysis, what is typical of cinematographic narration is not the subiectum and obiectum dichotomy (which is constantly emphasised and respected in the construction of a given message), but the ambivalence in the manner of representation. The issue here is the polar opposites uniting the narration, within which the factors subiectum and obiectum might appear not in turn or separately but together and concurrently, a point that is worth emphasising!

As a starting point, let us assume that we are dealing here with a working hypothesis, which should be carefully analysed in order to find the optimally extensive research aim that takes in film phantasmagoria from Reynaud, Méliès, Smith, Hepworth and McCay right up to the present day.

This observation has particular consequences in terms of methodology. It leads to the conclusion that cinematographic narration (irrespective of the specific character of the genre or the characteristics of a particular message that appear) never appears in a form that can be unequivocally deemed purely objective, just as it does not take on a $100 \%$ subjective form.

With this in mind, as viewers and film researchers, are we entirely helpless in the issue of objectivism, condemned from the very outset to arbitrarily random convictions and suppositions on the objective or subjective nature of complex narration from a series of moving images?

This not necessarily the case. It is necessary to set the viewpoint on narratological reflection differently: yes, in order to be able to connect the functional form of the communication and the speaker-receiver relations built into it with communication about the world. In view of such relations regarding the way reality is presented, film or, in the wider sense, cinematographic narration might be objectified (with the transparency maintained within it regarding the way of relating and clear distance to the events portrayed), or might go in the direction of full subjectivization of the communication. If it makes use of the latter variant, a subjective point of viewing and hearing is usually used (i.e. representation) designed in both narrator-protagonist relations and narrator-address narration.

Observation one: for as long as we have been dealing with the process of communicating (from street surveillance cameras and GPS satellite location systems, through esoteric art in the form of avant-garde film, original films and audiovisual performance presented on the screen or screens), what has always been evident is something of a duality in the complementary participation of both aspects. The "subjectivism" factor is backed up by the "objectivism" one and vice versa, although the proportions between them in a given shot, scene, sequence or the work as a whole might develop quite differently, and above all, proceed in a variable way, often influencing and interfering with each other.

Observation two: communicating through moving images, regardless of the manner of narration adopted and the nature of a given message, always locates the message between "I" and "I", even when its highly impersonalized and by definition anonymous forms come into play. This leads to the conclusion that the subjective aspect cannot be eliminated entirely, even in such extremely depersonalized cases.

Observation three: what we ourselves deem to be "objective" in the cinematographic message and what we deem "subjective" in it is on each and every occasion a consequence of a stated communicative and sociocultural convention (or agreement), a narrative convention that both the speaker and receiver use in their own way during the communication process. There is no such thing as an ontological safeguard of the "objective" or "subjective" narrative properties of the images on the screen. The images themselves exposed in different messag- 
es and various contexts, and also in the same message presented in different places might be used in the "objectivizing" and "subjectivising" function of the message.

It is said that film and moving images live through transformations. This changeability and transformation initiate, define and determine all forms of narration and the mode of narration by means of these. What is written into the description of the fundamental features of communication systems of cinematographic language is not only the alternation of narrative perspectives of the screen images of reality, but also their unparalled mobility and magical immediacy of this transformation as a feature distinguishing cinematography among other fields of arts and communication.

However, a medium constituting an objective instrument is not yet a message. The latter is the one containing a humanistic element. We all know the common expression "the camera's eye", but not all of us are aware of the paradox hidden within it. The camera does not communicate but merely records mechanically visual and sound images, like a projector, which projects them onto a screen. Both perform the function of useful apparatus.

In the communicating process and in semantics of any particular cinematographic message, what counts are the images, both as material and for conveying meaning. Seeking to establish the objectivism of visual presentation, we discover its subjectivization; likewise, when trying to establish subjectivization, we paradoxically come across objectivization. One does not occur in the structure without the other.

At this point, let us definitively reject the fallacious assumption that what we are dealing with in the process of audiovisual communication is either objective narration or subjective narration. Instead, let us introduce a completely different research perspective, in which moving images and narration that produce a work/ message/ communique combine an aspect of objectivization and subjectivization as a vital oppositorum or all cinematographic narration. In the process of communicating by means of moving images, one does not exclude the other, and a complete separation of both aspects does not apply, for the practice of presenting and portraying looks quite different.

Rejecting the dichotomous nature of objectivism and subjectivism of moving images generates cognitive dissonance, behind which is the established perception habit and the need to distinguish unequivocally both aspects on an either-or basis. And what if both were to be combined in a model fashion, perceiving in this not something incidental and facultative, but an all-encompassing functional property in the narration process in moving images, constituting its very deepest essence?

A scene phenomenally rich in nuances sparkling out of the masterfully worked narration concepts (the coin wobbling on the floor) can be found in the station scene from Krzysztof Kieślowski's masterpiece Blind Chance (1981). Here I am consciously glossing over the fact that the whole film (including its ending!) is a virtuoso performance in hypothetical narration, by the way creatively developing construction model already known from Kurosawa's Rashomon, Munk's Man on the Tracks, Buñuel's Tristan or Zanussi's television Hypothesis. Kieślowski created his own, unique brand of film narration in the suppositional mode, the core of which is the equal status and equality given to the protagonist Witek Długosz's successive fortunes as obseerved by the viewer.

In the version of the hypothetical narration model designed by Kieślowski, each of the stories organizes existential discourse around the choices made by humans and the crucial role played by the eponymous 'chance', whose immediate and distant consequences irrevocably determine the course of human life. The material for our analysis is not the entire film but that short sequence of events when the late-coming protagonist dashes into the station, buys a ticket, runs through the hall and chases a Warsaw-bound train down the platform.

This station sequence constitutes a pivotal point in the plot, and acts as the starting point for the unpredictable course of subsequent 
events that determine how the protagonist's life takes this turn and not another. The hypothetical triple nature of the action, returning at each step to its equally hypothetical beginning, is based on constructions such as: "it's possible that", "let's suppose...", "and if". Let us add that the final scene of the film, with the plane crash at Okęcie airport, also works along the same lines.

In each case, this presumptive mode, or if one prefers conditional mode, completely changs the character of the world being depicted. The fact that this is not a workshop exercise or spectacular exercise for directors is evidenced by the unusually thoroughly documented and portrayed contemporary and historical background to Krzysztof Kieślowski's Blind Chance." The variantal nature of the action would not be possible if the author did not bring together subjectivizing and objectivizing perspectives on the narration. The quintessence of this procedure lies in the sequence in which Witek chases the departing train, where internal and external modal frameworks of the narration clash.

By introducing the term ostensibly indirect narration as a term that is useful for narratological reflection on audiovisual communication, my focus is the process of creating and receiving moving images, which continually leads to an exchange of the internal and external aspect of depiction. Cinematographic narration is always dependent. This dependence is determined by a great number of diverse factors, such as the modal framework of the message, the viewer's position of viewing and hearing, the focus of the examination, etc.

What we understand by the term ostensibly indirect narration is a feedback model of narration in moving images that is based on a semantic game played out continually between the drive for objectivization and that for subjectivization of the cinematic message. In this model, there is no place for a dichotomous division into the isolated, distinct categories: objective narration and subjective narration. Nota bene, something of a reverse concept for ostensibly indirect narration might occur, and, vice versa, ostensibly indirect narration, or striving for objectivization of screen events.

Contrary to popular opinion, in communicating by means of moving images, no purely subjective nor objective narration occurs. Due to its unobvious nature, and the sum of presupposition and habits of thought that persist in film narratology, this statement deserves a more expansive commentary. Two fundamental questions appears: firstly, are these narrations mutually exclusive? Secondly, can they be associated and functionally connected in one and the same message?

The answer to both these questions seems somewhat surprising. Not only is it possible to connect subjectivizing and objectivizing narratives in different ways, in the practice of communicating this has long occurred and continues without interruption.

The relation between the element obiectum and subiectum in film and audiovisual communication is an exceedingly significant arrangement of semantic tension in the narration. This arrangement, in which the way of presenting the screen reality is reflected, contains within it the non-static division of both these elements, as well as their co-existence and constant oscillation of their properties. One does not exist in narration practice without the other. The conclusion is this: indirect and direct narration are categories that do not deserve completely separate status in the communicative practice of moving images.

The position is that although the polar opposites subiectum and obiectum exist virtually within the process cinematographic narration, this polarity is not an argument in favour of their absolute separation into either - or. What is more, strict delimitation between them is not possible. In seeking to prove one, we encounter the presence of the other, and vice versa. Hence, it is immeasurably more accurate to talk of a temporary (given shot, frame, scene, sequence etc.) striving for the objectivization of the message, or also of an analogous striving for its subjectivization. Expressed in other 
words, determinant objectivizing and subjectivizing factors occur in a given message or in any fragment of it, which might be the object of our functional analysis. The collisionary nature of both these factors and the unceasing tension between them constitutes an inexhaustible source of narrative invention in film and moving images.

\section{Narrative pendulum}

The communication game between the author and viewer's convictions regarding the objectivization or subjectivization of a given message, on one or another of the 'levels' on which it is constructed, does not derive from the nature of the medium, nor other features of cinematographic material, but is by nature conventional par excellence. The way it unfolds is designed into the narrative text by the sender and reconstructed by the receiver. It deserves emphasising at this juncture that it is not a question of an occasional effect of one shot or scene, but the pervading and constant oscillation of both types of factors within the boundaries of each and every message.

In seeking to identify and consider the incredibly important function and communicative significance of this feedback, our direct aim is to state that the narrative element in all types of moving pictures, from a desubjectivized surveillance recording to a multifariously subjective work of film, is neither objective narration nor its subjective polar opposite. The following question suggests itself: if this is so, then what is it? In each instance, the element of depiction is an ostensibly dependent narrative setting both these poles in motion, in various ways arranging and blending the participation of opposing aims and perspectives for communication.

The modal frame, the situation on the screen and the three interlinked perspectives - focus on the figure, focus on the narrator and the focus on the speaker/subject of the message - all come together in the message being conveyed to create a complex configuration of complementary and variable narrative perspectives. These aspects are not mutually exclusive, nor do they cancel each other out. Depending on the communicative needs (hence the spheres of "what?" and "how?" within the message), they generate a temporarily defined hierarchy of the validity and modus operandi of the narrative. On one occasion, precedence might be given to the desubjectifying and objectifying aspect of the message; elsewhere, it might be the opposite - the subjectifying screen statement.

However, what is always evident in the message is a certain tension in the communicative discourse in the continuum stretching between the poles of the narrative. To put it in general terms, from the perspective of the narrative produced, cinema and the media world are borderland territories, indirect cases, in their very nature ambiguous and ambivalent, in which what counts is one or another aspect of depiction, arranged, organised and expressed more or less individually through the language of cinematography.

In every instance, playing the screen game of "objectivism" and "subjectivism" is conventional in its nature, and this deserves to be emphasised once again. Whenever with regard to news programmes (with the anonymous voice of the speaker out of shot) or current affairs programmes (broadcast with the presenter participating neutrally) we think that this is completely transparent and totally objective, it transpires that this is always based on somebody's subjective decisions, devices or solutions relating to the narration (resp. Subject-based), which together impact on the way the content is presented.

It is also worth looking at this question once more from the historical poetics perspective. In the traditional cinematographic view, film narration developed from the model of the all-knowing and objective narrator to that of the subjective narrator. The former favoured an ostensibly transparent, impersonal record of internal reality, part of the apparatus for recording the film reality objectively. The latter model, on the other hand, concentrated on depicting the external world of a given character (protagonist, narrator, author) in the message 
being conveyed. But was this really the case? This idea of a simple and unambiguous evolutionary sequence in narration is not borne out by the film knowledge we have at our disposal.

The point is that a certain duality was evident in narrative operations even in cinema's early days. Emphasising their palpable ambivalence, what we are thinking about is the objective-subjective nature of the message, far more complex than is generally assumed (Reynaud, the films of Edison and the Lumière brothers, Méliès, Williamson, Porter, Griffith, Hepworth, $\mathrm{McC}$ ay etc.). And this remains the case right up to the present day.

Any camera recording of the screen reality subjected to more thorough narratorological analysis makes us aware that what we are not dealing with a dichotomy of completely mutually exclusive narrative variants, but with a unity of opposites, organising the communication process in a variety of more or less individualized ways, with the emphasis on the objectivization and subjectivization of the message.

In each case, we are also dealing with a significant contribution of combined, varied and clashing perspectives, deriving their energy from the coincidentia oppositorum effect. This mechanism works like a narrative pendulum it makes itself known by constructing internal and external frameworks that serve to organize the inspection demonstrated in moving images, a technique successfully attempted in the very earliest days of cinema and since then developed continually by film-makers.

Neither of these two possibilities ultimately comes out on top. As we have sought to show, neither exists without the other. This resulted in significant microsystemic semiotic effects for the course of narration by means of moving images. The practice of communicating comprised of a repertoire of all forms of cinematographic narration generally depends on combining the conventionalized opposites obiectum and subiectum (comprehensible for the viewer as taught perception models for reception).

The complicated relations between these in works of film are never-ending and in particu- lar cases might assume any level of complexity. Due to authors' inexhaustible invention, it is always possible to count on new and original variants on ostensibly dependent narration (and ostensibly independent). One such superbly designed variant in modern times is Bodo Kox's 2013 tragi-comedy "The girl from the wardrobe", a work of exquisite finesse and imagination in terms of the objectifying-subjectifying narrative solutions it employs, where the aspects are indivisible on the level of specific shots.

Essentially, what we are talking about here is a montage of narrative perspectives, correlated with each other, appearing simultaneously in a particular shot, scene and in the construction of the work as a whole. Studying the narratalogical mechanisms of montages of perspectives reveals the paradoxical duality of the manner of presenting the screen world, a duality that appears on various levels, and with it the network of semantic connections between subiectum and obiectum.

Ostensibly dependent narration is an analytical and operational category with regard to the sphere of moving images, and contains the following: a modal framework, point of view and of hearing (objectivizing or subjectivizing indicator of the message), as well as a defined screen situation. In film, as in in the whole field of moving images, there is no objective narration, just as there is no subjective narration. What emerges is ostensibly dependent narration (or ostensibly independent narration), blending and merging both these objectives in numerous ways. Like Monsieur Jourdain, cinema "spoke prose" (for this, read 'it used exactly this manner of narration'), for many years unaware of using it, or of the existence of the category itself.

Ostensibly dependent narration, like dependent and independent narration, does not result directly from the "very nature" medium. In cinematographic text, it constitutes a ubiquitous and universally clear convention of communicating. It might be varied in its nature: lyrical, dramatic, comic, grotesque, reflective, ironic etc. We encounter it in countless films from the classic cinema period: from "The 
Student from Prague", "Birth of a Nation" and "Intolerance", through "Blue Angel", "Gone with the Wind", "Stagecoach", "Casablanca" and "My Darling Clemetine". What can be discerned immediately in each of these works is the co-existence of objectivization and subjectivization of the matter presented.

A significant transformation of the form of ostensibly dependent narration came in the original films of the 1950 s and 6os, such as those by: Kurosawa, Buñuel, Welles, Bergman, Fellini, Antonioni, McLaren, Bresson, Ray, Lenica, Munk, Wajda, Has, Konwicki, Anderson, Truffaut, Godard, Pasolini, Polański, Tarkowski, Skolimowski, Forman, Menzel, Passer and other directors. Treating these names collectively for the purposes of showing a particular example should not be misleading. In effect, there were far more of them.

The creators of original cinema at that time discovered the numerous merits of a multifaceted and complementarily oriented ostensibly dependent narration raised to a higher level of reflection in film works. What contributed to the wider societal circulation of audiovisual culture at the time, and to the present day, was consent to a personal expression and point of view on the part of the director, as well as the right to a uniquely individual (variously objectified) artistic vision of reality, an unwritten right fiercely defended by generations of film-makers.

Translated by

Aleksandra Oszmiańska-Pagett and Rob Pagett

\section{B I B L I O G R A P H Y}

Bal M., Narratologia. Wprowadzenie do teorii narracji, trans. E. Kraskowska, E. Rajewska, Kraków 2012

Bordwell D., Narration in the Fiction Film, London 1985

Chatman S., Coming to Terms. The Rhetoric of Narrative in Fiction and Film. Ithaca, NY, 1990

Hendrykowski M., Semiotyka ruchomych obrazów, Poznań 2014

Hopensztand D., Mowa pozornie zależna w kontekście "Czarnych skrzydel", [in:] Stylistyka teoretyczna w Polsce, red. K. Budzyk, Warszawa 1946

Łotman J., O modelującym znaczeniu "końca" i "początku" w przekazach artystycznych (Tezy), trans. J, Faryno, [in:] Semiotyka kultury, red. E. Janus, M.R. Mayenowa, Warszawa 1975

Ostaszewski J., Historia narracji filmowej, Kraków 2018

Przylipiak M., hasło Narracja [in:] Słownik pojęć filmowych., vol. 5, ed. A. Helman, Wrocław 1993

Reinventing Film Studies, eds Ch. Gledhill, L. Williams, London 2000

Thanouli E., Post-classical Narration. A New Paradigm in Contemporary World Cinema, Amsterdam 2005 